\title{
ENSAIOS
}

\section{CONCEPÇÃO DE JUSTIÇA EM ÂNGELA DAVIS E NANCY FRASER: aproximações para uma crítica do capitalismo}

\author{
Annelyse Cristine Cândido Santos ${ }^{1}$ \\ Josiley Carrijo Rafael ${ }^{2}$
}

Resumo: $\mathrm{O}$ artigo tem como intenção traçar chaves de análise que nos permitam compreender a existência ou não de uma concepção de Justiça nas obras da filósofa, ativista e feminista negra norte americana Ângela Davis, e da filósofa, feminista, professora de Ciência Política e Social da New School de Nova Iorque, Nancy Fraser. As autoras apresentam em seus estudos, a interligação entre aspectos fundantes da sociedade, sistemas e formas de organização social, ancoradas na divisão de classes, opressão, com destaque à interseccionalidade de raça, classe e gênero para Ângela Davis, e do reconhecimento e redistribuição em Fraser. Apresenta inicialmente ume breve contextualização da distinção entre justiça e direito na sociedade capitalista, a seguir reflexões sobre concepção de justiça nas contribuições das autoras, possíveis intersecções entre Davis e Fraser e considerações finais com percepções sobre os achados nas elaborações. Buscar elementos preliminares sobre a concepção de justiça na obra das autoras acena para um horizonte de mudanças nas formas sociais, na busca de um significado crítico para a justiça no capitalismo.

Palavras-chave: Justiça; Gênero; Interseccionalidade.

Abstract: The article intends to trace keys of analysis that allow us to understand the existence or not of a conception of Justice in the works of the North American black philosopher, activist and feminist Angela Davis, and the philosopher, feminist, professor of Political and Social Science at New New York School, Nancy Fraser. The authors present in their studies, the interconnection between fundamental aspects of society, systems and forms of social organization, anchored in the division of classes, oppression, with emphasis on the intersectionality of race, class and gender for Ângela Davis, and the recognition and redistribution in Fraser. Initially, it presents a brief contextualization of the distinction between justice and law in capitalist society, followed by reflections on the conception of justice in the authors' contributions, possible intersections between Davis and Fraser and final considerations with perceptions about the findings in the elaborations. Seeking preliminary elements about the conception of justice in the authors' work points to a horizon of changes in social forms, in the search for a critical meaning for justice in capitalism.

Keywords: Justice; Genre; Intersectionality.

\footnotetext{
${ }^{1}$ Annelyse Cristine Cândido Santos, Mestranda em Política Social, Universidade Federal de Mato Grosso. Assistente Social do Ministério Público do Estado de Mato Grosso. E-mail: annecandido@gmail.com.

${ }^{2}$ Josiley Carrijo Rafael, Mestre em Educação, Doutor em Serviço Social. Docente do Departamento de Serviço Social e do Programa de pós-graduação em Política Social da UFMT. E-mail: josileyrafael@yahoo.com.br
} 


\section{Introdução}

O presente estudo partiu de inquietações sobre a compreensão de Justiça no R5 5 Capitalismo contemporâneo, sobre a maneira como essa terminologia é utilizada em discursos

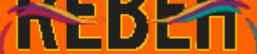

edprojetos políticos antagônicos. Em tempos de retrocessos de todos os direitos e da forte retomada do racismo, machismo e lgbtfobia, repensar o significado da justiça se coloca como tarefa urgente para construirmos estratégias de enfrentamento dos interesses burgueses. $\mathrm{O}$ primeiro e importante destaque diz respeito à concepção de Justiça, sendo necessária a distinção entre Justiça e Direito, os quais por muitas vezes são compreendidos, interpretados e defendidos como análogos: "fazer jurídico é fazer justiça". Assim, adiantamos que nossa filiação teórico-política está alicerçada na tradição marxiana e marxista, que nos possibilita compreendermos o conjunto das totalidades pela crítica da econômica política, pela convicção da possibilidade revolucionária, consequentemente pela dialética materialista.

A questão da justiça antecede o modo de produção capitalista, encontramos em Aristóteles uma sistematização filosófica, especificamente no Livro V da Ética a Nicômaco, apresentada em dois campos, no sentido universal e no sentido particular. Ao contextualizar sobre tais sentidos, Mascaro (2014), ilustra a relação entre caridade, paciência e justiça, pois “a caridade presume justiça, a paciência presume justiça, mas a caridade não presume paciência. A justiça está em todas as demais virtudes, e por isso é a única virtude universal”. No sentido particular, a justiça "compreende uma ação de distribuição, que demanda uma qualidade de estabelecer o que é de cada qual”, apresentando subespécies de justiça: justiça distributiva, justiça corretiva e reciprocidade (p.66-67).

É preciso, portanto, problematizar e avançar nos termos desta questão. Mascaro (2013) afirma que esse imbricamento de conceitos históricos e socialmente construídos se dá pela não compreensão das raízes sociais do que vem a ser Justiça e Direito, com especificidades intensificadas na contemporaneidade do capitalismo. O conteúdo da justiça é sempre histórico, atravessado por questões ideológicas que expressam os interesses de quem detém o poder, na linguagem marxista, os meios de produção. É por isso, que ao pensarmos nas elaborações filosóficas de Aristóteles e sua validade para o tempo presente, exige de nós o exercício de reconhecermos que "em cada um dos grandes modos de produção da história, chamou-se por justiça a sua exata reprodução social. Considera-se justo o que mantém a ordem existente" (p.192).

Por isso, a justiça que a sociedade comumente compreende/aceita é a justiça do/no capitalismo, no qual tem como raiz e motriz de funcionamento a "desigualdade na igualdade 
formal", e centralidade na ordem da exploração da força de trabalho. Já o direito, por si, compreendido como parte central do aparelho do Estado, tendo nele papel decisivo, atuando para a efetivação e legitimação da ordem social. Não é difícil nos deparar com ilações do tipo

"é natural e justo, um ter mais e outros menos, desde que com respaldo jurídico e legal". Destaca-se com isso que no capitalismo, a subjetividade jurídica se torna o cerne da reprodução do capital e, portanto, a institucionalização da forma jurídica é a reprodução daquilo que ocorre na forma mercadoria ${ }^{3}$ (MASCARO, 2018, p. 52-53).

A concepção de justiça aqui analisada, é aquela que precisa ser interpretada a partir de um horizonte mais amplo socialmente, e nele a luta pela superação da sociabilidade burguesa e de todas as opressões que se adequaram a esse modelo de produção e reprodução da vida social. Relegada ao próprio direito, a concepção burguesa de justiça, contribui para a manutenção, estruturação do capitalismo, que em sua essência é desigual e opressor. O direito nessa sociabilidade, por sua natureza, se torna uma forma social específica do capitalismo, e nele está a essência das mazelas de exploração e opressão da classe que dispõe tão somente da sua força de trabalho. Assim, feita essa primeira distinção, é necessário transcender a associação imediata entre Direito e Justiça, para compreendermos a essência da justiça possível na ordem burguesa, apontando interpretações que iluminam o enfrentamento das diversas formas de opressão.

Portanto, Estado e direito não são aparatos sociais consolidados, neutros e meramente técnicos, mas sim, correias de transmissão de movimentações gerais da dinâmica capitalista. Não raramente nos deparamos com a utilização de mecanismos jurídicos e judiciais para estratagemas políticos e capitalizações claramente ideológicas, sob o manto da neutralidade e do bem comum. Alguns deles, expressando avanços em sua aparência fenomênica.

Sartori (2010) deixa perceptível que as formas presentes no Direito escondem as contradições, as negatividades que o constituem, desse modo, o Direito projeta uma imagem que busca homogeneizar as desigualdades que estruturam esta sociedade. Defende ainda, que a busca por direitos deve ser parte importante da luta travada na vida cotidiana, marcada por desigualdades e disparidades sociais. Porém, para compreender a essência dos fenômenos sociais e não a sua aparência, é feito o processo de construção - reconstrução - desvelamento

\footnotetext{
${ }^{3}$ Tal subjetividade jurídica é uma equivalência entre pessoas, generalizando suas condições na base de uma liberdade contratual, de uma igualdade jurídica e de uma apreensão das mercadorias mediante respaldo previsto pelo Estado. Tal equivalência intersubjetiva, que forja materialmente a subjetividade jurídica, é espelho da equivalência das mercadorias, que se trocam tudo por tudo, tal como as pessoas se relacionam todas com todas e com tudo. Márcio Bilharinho Naves, definindo a forma de subjetividade jurídica, chama a forma de equivalência subjetiva autônoma. (MASCARO, 2017, p. 52)
} 
do fenômeno, e nele, é central a apreensão da similitude entre os fundamentos do capitalismo e do direito na sociedade.

Assim, apresentadas as distinções e correlações entre Justiça e Direito, para sua devida Fraser. As autoras demonstram uma certa sagacidade na interpretação crítica da realidade, o que nos provocou a buscar compreender as concepções de justiça expressadas por elas (ainda que essa diretamente não seja a categoria trabalhada pelas autoras). Assim, buscaremos dialogar com as autoras, enfatizando a relação "interseccional" entre ambas no que diz respeito à concepção de Justiça.

\section{A Injustiça Racial como face emblemática das opressões no capitalismo: indicativos preliminares da contribuição de Ângela Davis}

É notável nas obras de Ângela Davis, a presença das categorias mulher, raça, classes, relacionado com o processo de formação social e diversos contextos. Ganha destaque, pelo seu ativismo vívido e perceptível em suas produções, o olhar atento da particularidade do gênero, nessas condições, e ainda na dinâmica dos diversos processos de opressões inerentes ao capitalismo, articulante a questão do racismo com o sexismo.

A centralidade do papel das mulheres negras nas lutas históricas contra as explorações, também é outro elemento basilar nos escritos da autora, desde pincelar a sociedade comunal, às contradições do processo escravista/feudal, que se mantém no capitalismo. É presente a resistência histórica das mulheres negras em todos esses processos, ainda que em contextos e tipos variados de opressões. Davis enfatiza a interseccionalidade dessas, e destaca como a combinação delas colocam grupos em situações de maior vulnerabilidade social, agindo de forma entrecruzada não sendo possível hierarquizá-las.

Relevante enquanto método analítico, o destaque do conceito de classe, elevado ao concreto da vida pelas lentes do feminismo negro, o qual Davis é uma de suas expoentes. Nos estudos da autora, há a interseccionalidade da classe, com elementos fundantes como gênero e raça.

O professor Silvio Almeida (2015), ao buscar apresentar o "marxismo de Ângela Davis", aponta que, para a autora,

a escravidão e a servidão articularam-se de modo singular com o capitalismo nas mais distintas formações sociais, adaptando-se a diferentes realidades e costumes ou simplesmente dissolvendo e destruindo tradições não compatíveis com a lógica do capital. Assim, a divisão social e o conflito são marcas estruturais da sociedade capitalista, uma sociedade que só pode ser compreendida se dividida 
em classes, as classes em grupos, e os grupos em indivíduos, num processo permanente de classificação de indivíduos e de grupos sociais por critérios de pertencimento nacional, racial, sexual e de gênero que têm o Estado como principal artífice. Ao acentuar gênero e raça como componentes essenciais da categoria "classe", Ângela Davis contribuiu não apenas para a compreensão material do racismo e do sexismo, mas para o entendimento do capitalismo como sistema social em que a produção e a reprodução dos sujeitos, seja por meio da violência, seja por meio da formação de consensos ideológicos, é absolutamente imprescindível para a continuidade de uma vida social desintegrada e conflituosa (Grifos nossos).

Assim, o primeiro "direito humano", na sociabilidade do capital é a "vontade livre", presumidamente igual, para o contrato de exploração do trabalho assalariado, tão necessário para a reprodução social do capitalismo. Sobre esse aspecto, Davis (2016) faz um importante resgate no processo histórico das relações sociais no período escravagista, que em sua concepção, são as raízes do racismo social e estrutural, nas quais o capitalismo se assenta na atualidade.

Nesse período, as mulheres negras eram vistas, não menos do que homens, como unidades de trabalho lucrativa, sendo que para os proprietários poderiam ser desprovidas de gênero: "a mulher escrava era, antes de tudo, uma trabalhadora em tempo integral para seu proprietário, e apenas ocasionalmente esposa, mãe e dona de casa" (DAVIS, 2016, p. 17).

Por volta do século XIX, sete em cada oito pessoas escravizadas, tanto homens como mulheres, trabalhavam na lavoura, tratavam o solo, coleta de algodão, cortar cana, colher tabaco. Sobre esse trabalho a autora afirma,

no que diz respeito ao trabalho, a força e a produtividade sobre a ameaça do açoite eram mais relevantes do que questões relativas ao sexo. A opressão das mulheres era idêntica a dos homens, com o acréscimo do abuso sexual e outros maus tratos bárbaros especificamente cometidos contra as mulheres negras escravas. $\mathrm{O}$ estupro era uma expressão ostensiva do domínio econômico do proprietário e do controle do feitor sobre as mulheres negras na condição de trabalhadoras. (Idem, p. 20)

Djamila Ribeiro (2016) afirma que é salutar Davis iniciar sua análise pela escravidão porque,

a mão de obra escrava representava muito para a economia da época e mostra como o racismo é um elemento estruturante e deve ser tido como fundamental para uma análise profunda de sociedades com herança escravagista. Uma análise econômica deve passar necessariamente por essa questão pelo fato do racismo ser uma de suas bases de sustentação. Guardadas as devidas proporções, podemos falar sobre essa relação no Brasil, país com mais de 354 anos de escravidão negra e último do mundo a aboli-la. Logo, não se pode fazer uma leitura de opressão de classe que desconsidera o racismo, elemento fundante dessa sociedade. Assim como da opressão de gênero. Ângela Davis consegue capturar de forma profunda e sofisticada as nuances das diferentes formas de opressão e mostrar como elas agem e ainda constituem a sociedade. 
A luta abolicionista contava com a participação ativa das mulheres, através de resistências em guerras, sabotagens, libertação, mas também em forma sutil como ler, escrever, transmitir aos demais, compreendendo ainda, a opressão vivida pessoalmente e por

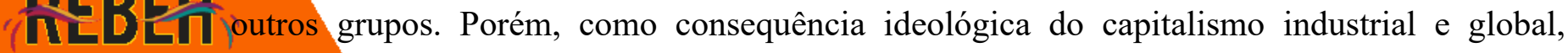
desenvolveu-se uma ideia mais rigorosa da inferioridade feminina, pois o prestígio da mulher branca começa a se deteriorar com o processo de industrialização, as tarefas antes produtivas no interior do lar, passam a ser exercidas pela indústria.

Na obra de Davis, Mulheres, classe e raça (2016), ganha notoriedade a presença constante do racismo estrutural, tanto nos processos de exploração escravagista, capitalista, como no interior do movimento abolicionista. Ao tratar das condições de trabalho no contexto estadunidense, destaca que homens e mulheres do movimento que "viam a escravidão como uma instituição intolerável e desumana, uma transgressão arcaica da justiça. Mas não reconheciam que a mão de obra branca do Norte, não obstante sua condição de operárias ou operários "livres", não estavam em situação muito diferente da mão de obra escrava do Sul: ambas eram vítimas de exploração econômica". (p.74-75)

A relação entre raça e a condição da mulher eram tratadas sem considerar os processos de exploração que passavam assumir novas determinações com o avanço do modo de produção capitalista. Impactando de maneira inédita nas novas configurações das relações de trabalho para as mulheres em geral, fazendo com que as análises sobre o trabalho livre não conseguissem extrapolar os limites da escravidão, ou seja, mesmo com a abolição, a liberdade lançada para as negras e aquela já vivenciada pelas mulheres brancas, continuava a ser uma liberdade limitada, onde seus corpos continuavam a reproduzir uma nova forma de exploração pela via do trabalho assalariado.

\footnotetext{
Como regra, pessoas brancas abolicionistas ou defendiam os capitalistas industriais ou não demonstravam nenhuma consciência de identidade de classe. Essa aceitação sem objeções do sistema econômico capitalista era evidente também no programa do movimento pelos direitos das mulheres. Se a maioria dos abolicionistas viam a escravidão como um defeito indecente que precisava ser eliminado, a maioria das defensoras dos direitos das mulheres enxergava a supremacia masculina de forma similar - como uma falha imoral de uma sociedade que, em seus demais aspectos, era aceitável. [...] No interior do movimento de mulheres, em seus primeiros anos, pouco se discutia sobre a população branca trabalhadora - nem mesmo sobre as mulheres brancas trabalhadoras. Embora muitas mulheres apoiassem a campanha abolicionista, elas não conseguiam integrar sua consciência antiescravagista à análise que faziam da opressão das mulheres (DAVIS, 2016, p. 75).
}

De igual modo, com a presença do racismo estrutural na sociedade pré-industrial, Davis (idem) destaca a intersecção deste com o sexismo, interpretando-os como elementos 
centrais da estratégia doméstica de aumentar a exploração econômica. Tanto que, "a proliferação da violência sexual se torna a face brutal de uma intensificação generalizada do sexismo, que necessariamente acompanha essa agressão econômica” (p.202). Nesse contexto, trabalhadora. Para Davis (2016),

\begin{abstract}
As enervantes obrigações domésticas das mulheres em geral oferecem uma flagrante evidência do poder do sexismo. Devido à intrusão adicional do racismo, um vasto número de mulheres negras teve de cumprir as tarefas de sua própria casa e também os afazeres domésticos de outras mulheres. E com frequência as exigências do emprego na casa de uma mulher branca forçavam a trabalhadora doméstica a negligenciar sua própria casa e até mesmo suas próprias crianças. Enquanto empregadas remuneradas, elas eram convocadas a ser mães e esposas substitutas em milhões de casas de famílias brancas (p. 239).
\end{abstract}

Essa realidade contribuiu para o desencadeamento de organizações que buscavam atuar no enfrentamento da realidade que demonstrava a face da opressão pelo intercruzamento entre racismo e sexismo. A luta por direitos relacionados ao trabalho doméstico é a luta pela por uma concepção de justiça, que entende hierarquias tanto pela condição feminina quanto pela condição de negra. Porém, ao analisar as bandeiras de lutas travadas pelos sujeitos coletivos que buscaram respostas para essa injustiça, Davis (2016) argumenta que o "Movimento pela Remuneração das Tarefas Domésticas" é revestido de contradições que exigem análises cuidadosas sobre o potencial de suas ações rumo a "uma estratégia concreta para a libertação feminina”.

Ainda que tais requisições fossem e sejam bases para a construção de relações de trabalho mais justas, do ponto de vista da comparação com outros tipos e perfis de trabalho, requisitando novos postos de emprego, melhorias nas condições salariais e etc., "a escravidão a uma linha de montagem não é si a libertação da pia da cozinha, mas a linha de montagem, sem dúvida, é o mais poderoso incentivo para que a mulher pressione pela eliminação de sua antiga escravidão doméstica" (idem). É essa análise que possibilita Davis (2016) apontar que a abolição das atividades domésticas como responsabilidade das mulheres, se constitua num profícuo caminho estratégico da "libertação feminina" (p.244), que poderá colocar em xeque o capitalismo, apontando novas trilhas em direção ao socialismo.

Outro elemento importante, que nos leva a possíveis aproximações quanto à concepção de Justiça presente em alguns escritos da autora, é a argumentação sobre o mito do Estuprador Negro, sendo identificados na forma de processamento seletivo jurídico dos estupros ocorridos após Guerra Civil, e a resposta social repressiva, a um público específico 
“culpado", através do linchamento da população negra. Para a autora, a seletividade no processamento, interpretação e julgamento dos processos de estupros nos Estados Unidos, se tornaram um manto justificador social da eliminação da população negra, por intermédio da opôe ao mito" a autora argumenta,

\begin{abstract}
Antes que os linchamentos pudessem ser consolidados como uma instituição popularmente aceita, entretanto, a barbaridade e o horror que representavam precisavam ser justificados de maneira convincente. Essas foram as circunstâncias que engendraram o mito do estuprador negro - pois a acusação de estupro acabou por se tornar a mais poderosa entre as várias tentativas de legitimar os linchamentos de pessoas negras [...]. Dessa forma, a brutal exploração da força de trabalho negra estava garantida e, após a traição da Reconstrução, a dominação política do povo negro como um todo estava assegurada. [...] os linchamentos eram uma forma contrainsusrgência sem disfarces, uma garantia de que o povo negro não conseguiria alcançar seus objetivos de cidadania e igualdade econômica (DAVIS, 2016, p. 202).
\end{abstract}

Para a autora, o mito do estuprador negro, possui conotação ideológica e invenção política, baseada no racismo estrutural, sendo ainda pano de fundo para implementação de ideologias, preconceitos e mortes. De igual modo, Davis (2016) apresenta uma importante inquietação acerca da forma com que ocorre o processamento do direito e suas instituições no capitalismo, pois, passam a tratar exclusivamente os homens negros como vilões e responsáveis pelo caos em torno da crescente violência sexual.

A lente crítica na interpretação da realidade faz com que a autora reivindique que não é possível compreender a verdadeira manifestação dos fenômenos sociais, sem tocar a fonte e situá-las em um contexto sociopolítico - econômico mais amplo. Dialogando com o tema do mito do estuprador negro, afirma que "apesar das estatísticas alarmantes, a incidência da condenação de estupradores é apenas de $4 \%$ e tais condenações representam apenas um percentual insignificante dos estupros que são de fato reportados" (DAVIS, 2017, p. 45). De igual modo, problematiza sobre a infiltração do racismo nas posturas sociais "em consequência da história de racismo onipresente da aplicação das leis nesse país, há nas prisões um número desproporcional de homens negros condenados por esse crime.” (Idem, p. 46).

Outro ponto de destaque na obra de Davis, que traz elementos para construirmos interpretações teóricas sobre sua possível concepção de Justiça, é a crítica que a autora faz ao sistema judicial e às discussões acerca do abolicionismo penal. Ainda que, os operadores do sistema judicial, ou a instituição judicial em si, não signifique falar sobre o sentido stricto sensu de Justiça, se reveste de importância as reflexões da autora, por entender sua relação 
com a escravidão e ser um mecanismo de encarceramento em massa da população negra na contemporaneidade.

Levando em consideração que nos últimos anos aumentou significativamente o número de mulheres negras encarceradas tanto no Brasil como nos EUA, Davis evidencia o fato importante de também se pensar a categoria de gênero nessa equação. Em "A prisão como fronteira: uma conversa sobre gênero, globalização e punição", Davis diz "[... ]estamos reconceitualizando a relação entre o Complexo Industrial Carcerário e a globalização - desde uma discussão de como a prisão está sendo afetada pela globalização da economia (em que a prisão se encaixa na globalização) até a utilização da prisão como uma instituição histórica contingente que não só prognóstica/pressagia a globalização, mas nos permite pensar hoje sobre as intersecções entre punição, gênero e raça, dentro e além das fronteiras dos Estados Unidos" (RIBEIRO, 2016).

Tais elaborações, com destaque para sua obra "Estarão as prisões obsoletas", no qual revela que o sistema penal, e a seletividade jurídica dos que são penalizados seria uma forma de escravismo, conceituando de forma análoga o período de escravidão e o que denomina de atual complexo industrial - prisional. Destaca que isso ocorre porque, o racismo define estruturalmente o trabalho das polícias, dos operadores, das políticas repressivas de segurança, que levam ao encarceramento de pessoas negras. A autora acrescenta ainda, que para fazer frente ao processo de encarceramento da população negra, é necessário perspectivar a prisão a partir da inspiração abolicionista, sendo contrário a instrumentos de perpetuação da violência como ocorreu na escravidão com o linchamento e segregação da população.

A autora apresenta uma análise do recorte de gênero nas unidades prisionais, afirmando que os arranjos da prisão são moldados sem levar em conta as particularidades do gênero feminino, pois é pensada a partir do prisma masculino, o objetivo de recuperação social de condenadas se dá de acordo com os padrões hegemônicos de feminilidade. Neste sistema, as atividades das condenadas na prisão são voltadas ao trabalho doméstico, à culinária, sem muito considerar outras possibilidades de reintegração profissional.

A análise de tais ocorrências, de forma interseccional entre gênero, raça e classe, consiste em resposta estrutural, política e intelectual do feminismo, à dinâmica da violência, supremacia branca, patriarcado, poder do Estado, mercados capitalistas e políticas imperiais, que tem como resultados a segregação, lucros, sensação de segurança.

Desta forma, para Davis, pensar o projeto de outra sociabilidade é necessário considerar a centralidade da questão racial, conexões entre as expressões históricas do racismo e o estado atual das instituições prisionais, não hierarquização das opressões, considerando a intersecção entre raça, classe e gênero para possibilitar um novo modelo de sociedade. Isso fica evidente na coletânea "A liberdade é uma luta constante", no conteúdo do 
discurso realizado na Davidson College. Davis (2018) chama atenção para as pautas que se pulverizaram e se mostraram tão somente no campo da defesa dos direitos civis no movimento pela liberdade negra. Para a autora, "a liberdade é ainda mais ampla do que os

direitos civis", a luta pela liberdade deveria ter se atentado para a dimensão macroscópica da vida social e econômica.

Era uma questão de liberdades concretas. Era uma questão de educação gratuita. Era uma questão de assistência à saúde gratuita. Moradia a preço acessível. Essas são questões que deveriam ter integrado a pauta abolicionista do século XIX, e cá estamos, no século XXI, ainda sem poder dizer que temos moradia e assistência à saúde a preços acessíveis - e a educação se tornou uma mercadoria (p.11-112).

As observações lançadas por Davis (2018), podem ser tratadas como conquistas que deveriam ter sido galgadas na luta pela liberdade, mas que não se limitasse a pura e simples liberdade formal. Ao apontar sua compreensão sobre "liberdades concretas", a autora sinaliza novamente chaves de análise para pensarmos como a questão da justiça aparece em seus textos e como isso deve ser compreendido pelos seus leitores e interlocutores. Para Davis (2018), a alforria não promoveu justiça e equiparação, é isso que faz a autora encerrar um dos seus textos, tomando emprestado uma frase de Martin Luther King. Para ela, há um princípio que precisa ser central nas diversas maneiras de engajamento, esse princípio "deveria ser o lema de todos os movimentos: a justiça é indivisível. A injustiça em qualquer lugar do mundo é uma ameaça à injustiça em todo o mundo" (p.117).

\section{Justiça requer Redistribuição e Reconhecimento: contribuições de Nancy Fraser}

Para uma análise da contribuição de Nancy Fraser (2017), filósofa feminista, vinculada à teoria crítica, e com produções dedicadas à articulação de formas diferenciadas de analisar o capitalismo, é presente a concepção e análise da economia não como um subsistema, mas como uma ordem institucional abrangente. Também é notado em seu caminho, as críticas aos equívocos da esquerda, em especial "pós socialista"4, bem como o desenho de novas estratégias e táticas, ao destacar gênero, raça e classe (em suas palavras - as diferenças étnicas culturais), sem a conexão dessas, com a economia ${ }^{5}$. A temática gênero para a feminista é abordado no contexto dos dilemas enfrentados pelas teorias contemporâneas de

\footnotetext{
4 "Está associada à transição do capitalismo industrial ao financeirizado - e, portanto, à ineficácia das antigas estratégias de resistência, que se baseavam na ação dos trabalhadores organizados” (FRASER, 2018).

${ }^{5}$ A autora desenvolve na sua fundamentação teórica, diversos outros conceitos, debates, inflexões. Porém, nos ateremos no presente artigo à concepção de Justiça baseado na interconexão entre reconhecimento, redistribuição e brevemente representação.
}

Vol. 02, N. 03, Jul. - Set., $2019 \cdot$ www.revistas.unilab.edu.br/index.php/rebeh 
justiça, e dessa forma, visualiza-se a centralidade da problemática da justiça em suas elaborações, o qual, buscaremos destacar as principais acepções.

Fraser faz uma análise "por dentro" do feminismo, e identifica que este, especialmente 250 "T는 RENSTA BRASILERA DE ESTUDOS DA HOMOCULTURA coaadunar com interesses hegemônicos, vez que priorizou pautas relativas a questões de identidade/reconhecimento, tirando a seu ver, o foco de uma pauta mais antiga que era redistributiva/econômica. Para a autora, essa guinada identitária foi ao encontro das políticas neoliberais em curso, e dos processos de reorganização econômica diante da crise do capital, que passou então, a se flexibilizar e intencionar atender à financeirização que se desenhava. Depreende-se das análises, que o destaque ao reconhecimento e identidade no interior do movimento feminista, se encaixou como uma luva nos esforços neoliberais, e ainda, contribuiu para distanciar o feminismo do socialismo, sua raiz e essência transformadora. Assim e, portanto, a autora identifica uma ligação perigosa desse movimento aos esforços neoliberais do capital almejando enfrentamento à mais uma de suas crises.

Em "O feminismo, o capitalismo e a astúcia da história", analisa essa questão e faz um recorte de três fases:

Se na primeira fase, a crítica feminista ao capitalismo integrava três dimensões: econômica, política e cultural, e, naquele período, as feministas tinham como horizonte um projeto político transformador, a segunda fase coincide com a falência do modelo do Estado de bem-estar social e a emergência do neoliberalismo. Assim, ela mostra, não sem dilemas e debates ${ }^{6}$ no interior do próprio feminismo, como algumas das reinvindicações desta segunda fase foram instrumentalizadas e incorporadas pelo neoliberalismo (TADINI, 2018).

Em que pese a crítica, a autora reconhece que as feministas da segunda onda ampliaram o campo de ação da justiça de gênero, para incluir assuntos anteriormente privados como sexualidade, serviço doméstico, reprodução e violência contra mulheres (FRASER, 2009).

A partir dessa análise, crítica e polêmica no interior dos feminismos, Fraser (idem) propõe uma "correção de rota", na qual almeja alcançar um paradigma mais rico e mais amplo: conectar redistribuição e reconhecimento, como uma possibilidade de análise da questão de gênero, e com ela abrigar todas as pautas feministas, de forma não excludente.

\footnotetext{
${ }^{6}$ Um dos debates sobre o tema: "Entretanto, no contexto de um neoliberalismo ascendente, as lutas feministas por reconhecimento podem estar servindo menos para enriquecer as lutas por redistribuição do que para substituí-las. Assim, em vez de alcançarem um paradigma mais amplo e rico, que poderia abranger tanto redistribuição quanto reconhecimento, as feministas parecem ter trocado um paradigma truncado por outro - um economicismo truncado por um culturalismo truncado" (FRASER, 2007, p.21).
}

Vol. 02, N. 03, Jul. - Set., $2019 \cdot$ www.revistas.unilab.edu.br/index.php/rebeh 
Demarcando ser uma tarefa intelectual e militante, construir uma justiça que abarque tanto reconhecimento quanto redistribuição, nos escritos " $\mathrm{Da}$ redistribuição ao reconhecimento? Dilemas da justiça na era "pós-socialista", Fraser (2002), afirma que a luta

por reconhecimento se tornou paradigmática de conflito político no fim do século XX. Entende a importância do conceito, pois, demandas por reconhecimento das diferenças alimentam a luta de grupos mobilizados sob importantes bandeiras, como da nacionalidade, etnicidade, raça, gênero e sexualidade.

Para Fraser, e aqui ao nosso ver, está a centralidade da concepção da autora, a efetivação de justiça no capitalismo contemporâneo se dá principalmente pela existência e interconexão de redistribuição, reconhecimento e representação, pois, há a caracterização da totalidade social na sociedade capitalista organizada pelo Estado de forma androcêntrica ${ }^{7}$, está estruturada por três ordens inter-relacionadas de subordinação: (má) distribuição, (falta de) reconhecimento e (falta de) representação.

Assim, a injustiça de gênero, possui duas causas: material/econômica e cultural/simbólica, que ao seu ver, se encontram imbricadas e se reforçam continua e sucessivamente. Destaca que normas sexistas e androcêntricas são institucionalizadas na política e na economia, tendo como resultado, o silenciamento cultural e exclusão material, de forma que a subordinação econômica e material mantém entre si uma relação perversa.

O conceito de redistribuição, sumariamente, busca uma alocação mais justa de recursos e bens, buscando-se redistribuir a riqueza dos ricos para os pobres, do Norte para o Sul, e dos proprietários para os trabalhadores.

A orientação redistributiva tem uma linhagem filosófica clandestina, já que as
reivindicaçôs redistributivas igualitárias forneceram o caso paradigmático para a
maior parte da teorização sobre justiça social nos últimos 150 anos. A orientação do
reconhecimento recentemente atraiu o interesse dos filósofos políticos e, alguns
entre eles, têm buscado desenvolver um novo paradigma normativo que coloca o
reconhecimento em seu centro (FRASER, 2007, p.102).

Essa situação exemplifica um fenômeno mais amplo: a difundida separação entre a política cultural e a política social, a política da diferença e a política da igualdade. Em alguns casos, além disso, a dissociação tornou-se uma polarização. Alguns proponentes da redistribuição entendem as reivindicações de reconhecimento das diferenças como uma "falsa consciência", um obstáculo ao alcance da justiça social. Inversamente, alguns proponentes do reconhecimento rejeitam as políticas redistributivas por fazerem parte de um materialismo fora de moda que não consegue articular nem desafiar as principais experiências de injustiça. Nesses casos,

\footnotetext{
7 "Seguiu-se que a cultura política do capitalismo organizado pelo Estado visualizava o cidadão de tipo ideal como um trabalhador masculino pertencente à maioria étnica - chefe e homem de família. Foi amplamente suposto, também, que o salário deste trabalhador deveria ser o principal, se não o exclusivo, sustento econômico de sua família, enquanto quaisquer salários ganhos pela sua esposa deveriam ser meramente suplementares". (Fraser, 2009, p. 16)
} 
realmente estamos diante de uma escolha: redistribuição ou reconhecimento? Política de classe ou política de identidade? Multiculturalismo ou igualdade social? (FRASER, 2007, p. 102-103).

Justiça, hoje, requer tanto redistribuição quanto reconhecimento; nenhum deles, sozinho, é suficiente. Sustento que os aspectos emancipatórios das duas problemáticas precisam ser integrados em um modelo abrangente e singular. A tarefa, em parte, é elaborar um conceito amplo de Justiça que consiga acomodar tanto as reivindicações defensáveis de igualdade social quanto as reivindicações defensáveis de reconhecimento da diferença (FRASER, 2007, p.103 - Grifos nossos).

Ligeiramente, o conceito de Reconhecimento, apresenta preocupações relacionadas à ordem de status da sociedade e às hierarquias de status culturalmente definidas, buscam o reconhecimento das distintas perspectivas das minorias étnicas, raciais e sexuais, bem como a diferença de gênero. A meta principal seria um mundo que acolha amistosamente as diferenças, "um mundo onde a assimilação nas normas culturais majoritárias ou dominantes não seja mais o preço que se tenha de pagar por igual respeito” (FRASER, 2002, p.7).

Dessa forma, para Fraser, uma concepção ampla da Justiça, deve ser orientada tanto pela redistribuição quanto reconhecimento, sem reduzir um ao outro. Dessa perspectiva, o reconhecimento é um "remédio" para a injustiça social e não a satisfação de uma necessidade humana genérica.

Dessa maneira, a(s) forma(s) de reconhecimento que a justiça exige em qualquer caso dado depende(m) da(s) forma(s) de não reconhecimento a serem compensadas. Nos casos em que o não reconhecimento envolve a negação da humanidade comum de alguns participantes, o remédio é o reconhecimento universalista; assim, a primeira e mais fundamental compensação para o apartheid sul-africano foi a cidadania universal "não-racializada" (FRASER, 2007, p.121).

Ao ampliar o paradigma usual da justiça, eu tratei a redistribuição e o reconhecimento como duas dimensões mutuamente irredutíveis da, e perspectivas sobre, a justiça, ambas podendo ser subsumidas à norma comum da paridade participativa. (FRASER, 2007, p. 123 - Grifos nossos).

Nesse caso, como já vimos, na lei matrimonial, a institucionalização de uma norma cultural heterossexista nega a paridade de participação a gays e lésbicas. Para o modelo de status, então, essa situação é patentemente injusta, e uma reivindicação por reconhecimento é, em princípio, justificada. Tal reivindicação busca remediar a injustiça por meio da desinstitucionalização do padrão de valor heteronormativo e sua substituição por uma alternativa que promove a paridade. Isso, contudo, pode ser feito de mais de uma maneira. Uma forma seria garantir às parcerias homossexuais o mesmo reconhecimento de que as parcerias heterossexuais, hoje em dia, desfrutam, legalizando o casamento entre pessoas do mesmo sexo. Outra forma seria desinstituticionalizar o casamento heterossexual, desvinculando direitos, tal como seguro-saúde da condição marital, e prescrevendo-os sob alguma outra base, tal como a cidadania e/ou a residência territorial. (FRASER, 2007, p.126).

Acena para a possibilidade de consecução das duas propostas, sem se tornar, porém, uma "esquizofrenia filosófica", sendo ao seu ver possível acomodar as reinvindicações por 
igualdade econômica e por reconhecimento da diferença (Idem). Proporei uma "abordagem não culturalista às políticas de reconhecimento e uma revisão de suas relações com a economia. Apenas tal abordagem, defendo eu, permite integrar redistribuição e

Benefícios dirigidos especificamente para pobres são a forma mais diretamente redistributiva da seguridade social. No entanto, tais benefícios tendem a estigmatizar os recipientes, fazendo que sejam vistos como transviados e parasitas, distinguindoos negativamente dos que "ganham salários" e dos "contribuintes" que "arcam com suas próprias custas". Os programas de bem-estar desse tipo "visam" ao pobre não apenas para ajuda material, mas também para a hostilidade pública. Frequentemente o resultado final agrega à injúria da privação e o insulto do reconhecimento inapropriado. As políticas redistributivas tem efeitos de reconhecimento inapropriado quando os padrões subjacentes de valor cultural desviam o sentido das reformas econômicas quando, por exemplo, há uma desvalorização generalizada da mulher que cuida dos seus como alguém que "ganha alguma coisa sem fazer nada". Neste contexto, a reforma do bem estar não terá sucesso se não vier unida a lutas por mudança cultural que visem a reavaliar, por exemplo, o cuidado das crianças e as associações femininas que o codificam. Em resumo, nenhuma redistribuição sem reconhecimento (FRASER, 2017, p.25).

No quesito representação, é importante destacar a visão feminista da autora, na qual almeja uma democracia menos excludente e mais plural, propondo rever a concepção modelo do sujeito moral masculino que a sociedade privilegia, e com isso, nega uma visão sexista, a partir da inserção das mulheres na esfera pública e processos decisórios, que carregam no seu bojo a definição dos rumos das políticas.

Desta forma, Fraser pensa de uma nova maneira a relação entre Redistribuição (presente na história do Feminismo), Reconhecimento (ascendente, com auge na segunda onda do feminismo e presente nas contribuições feministas da atualidade) e Representação, conectando-as com o intuito de mudar o paradigma desigual de gênero na sociedade, e com isso acender ao que defende como Justiça Social.

\section{A "interseccionalidade"8 entre a concepção de Justiça em Davis e Fraser}

Analisando as contribuições das autoras, é visível o lastro crítico, político, ativista e acadêmico de ambas, colados a uma vida dedicada ao movimento feminista dos Estados Unidos, que repercutiram na consolidação do feminismo pelo mundo.

Nas contribuições de Ângela Davis, se destaca uma perspectiva revolucionária sempre com nítida postura anticapitalista, denuncia o sexismo e comprometida com a luta antirracista,

\footnotetext{
${ }^{8}$ Aqui, a utilização do termo interseccionalidade no sentido de intersecção: conjunto de elementos que, simultaneamente pertencem a dois ou mais conjuntos.
}

Vol. 02, N. 03, Jul. - Set., $2019 \cdot$ www.revistas.unilab.edu.br/index.php/rebeh 
analisando como o racismo, capitalismo e sexismo estruturam as relações gerando formas combinadas de opressão. De igual modo, o impacto do racismo estrutural como fundamento das sociabilidades, e na concepção de Justiça (e por vezes a falta dela). Em algumas de suas

reflexões, o direito como norma serviu como mecanismo de garantia da libertação da mão de obra escrava para relações assalariadas. Igualmente evidente a crítica à seletividade jurídica, como a cultura do "negro estuprador"; a cor e raça daqueles que são condenados pelo sistema penal; o papel da mulher/gênero nesses processos, observando a necessidade de olhar interseccional entre gênero, raça e classe, para o devido enfrentamento dessas desigualdades sociais.

Especificamente em sua contribuição sobre o "mito do estuprador negro", demarca a visão fundante do racismo estrutural presente na sociedade, e argumenta,

Mas em primeiro lugar, por que existem tantos estupradores anônimos? Não seria
esse anonimato um privilégio usufruído pelos homens cuja condição social os
protege de processos judiciais? Embora os homens brancos que são empregadores,
executivos, políticos, médicos, professores universitários etc. sejam conhecidos por
"tirar vantagem" de mulheres que eles consideram socialmente inferiores, seus
delitos sexuais raramente vêm à luz em tribunais (DAVIS, 2016, p. 201).
O mito do estuprador negro faz com que as pessoas desconheçam as realidades do
estupro e o fato de que, por exemplo, mais de $90 \%$ de todos os estupros são
intrarraciais e não inter-raciais. Proporcionalmente mais homens brancos estupram
mulheres negras, do que homens negros estupram mulheres brancas (DAVIS, 2017,
p.46).

Dialogando com essa reflexão de Davis no ano de 1940, e a tradução brasileira apenas ocorrida em 2017, ou seja, 77 anos depois, observamos o quanto essa concepção ganha contornos intensificados na realidade brasileira, e mais ainda, no sistema jurídico brasileiro. $\mathrm{O}$ mito do estuprador negro é tão presente e arraigado, que causa estranheza social, no tempo presente, vir à tona investigações policiais emblemáticas, de crimes de estupro e violência sexual, com denúncia de terem ocorrido na década de 70, e apenas recentemente relatados, cometidos em tese por homens brancos, como os casos de João Teixeira de Faria e Roger Abdelmassih. Por que só agora? O que há de anônimo nessas apurações? O que há de riscos nas denúncias pelas vítimas? Tem correlação com a questão de raça, gênero e classe? Ficam as inquietações. Seguindo a linha de questionamento de Davis (2017) é bastante provável que esses homens de classe média/alta, sejam responsáveis pelos estupros anônimos/não notificados?

No que concerne ao estudo da autora sobre o encarceramento da população negra, verifica-se que segundo dados do Infopen (Sistema de informações do Sistema Penitenciário 
brasileiro, 2014), em números absolutos, o Brasil está em quinto lugar na lista dos 20 países com maior população prisional feminina do mundo, atrás dos Estados Unidos (205.400 detentas), da China (103.766) Rússia (53.304) e Tailândia (44.751). A população carcerária e, ainda, $61,67 \%$ é de negros ou pardos, com baixa ou nenhuma escolaridade. $40 \%$ do total (quase 250 mil) é de presos provisórios, ou seja, pessoas que se encontram cerceadas em sua liberdade sem terem sido julgadas (INFOPEN, 2014).

A autora aponta uma correlação entre justiça e encarceramento de gênero e raças específicas, dialogando assim, ao nosso ver com a seletividade jurídica e a impossibilidade de pelo direito, apenas e tão somente como norma jurídica, se buscar a efetiva Justiça,

\begin{abstract}
Permite-se vislumbrar que as crises do capital estão perpassadas, necessariamente, por instituições jurídicas. Com isso, não é o direito uma possibilidade de salvação nem de superação do capitalismo, como se outro conjunto normativo pudesse transformar a reprodução econômica. Quantidades distintas de direitos -como os direitos sociais - não logram se opor à qualidade capitalista da própria forma jurídica. O direito participa, enquanto forma estrutural, de uma dinâmica social que, plantada na exploração e na contradição, é por sua natureza portadora de crises. Daí, não se pode vislumbrar, pelo campo do direito, um potencial transformador nem superador do capitalismo. Os instrumentos jurídicos, quando muito, reconfiguram os termos da própria crise, dinamizando-a, alijando grupos, remediando ou protegendo outros, mas sempre promovendo um circuito infinito de trocas mercantis. Onde há mercadoria, nas bases específicas da produção capitalista, há direito e há crise, e nenhum desses termos é oposto aos outros (MASCARO, 2018, p. 54).
\end{abstract}

Em Davis, a intersecção entre raça, gênero e classe, tem ligação direta com todas as estruturas de poder existentes em determinada sociedade, e quando apresenta a injustiça racial e estrutural presente na sociedade contemporânea, o faz com elementos de realidade, pois, aponta que não é possível combater qualquer tipo de violência e opressão sem desmontar o capitalismo, se explicando por fatores históricos (nunca houve capitalismo sem racismo e sexismo) ou lógicos (não há capitalismo sem racismo e sexismo).

Já para Fraser, as lutas contra o sexismo e racismo não buscam transformar a ordem de status, já que gênero e raça também implicam estrutura econômica. Em suas elaborações é perceptível a concordância crítica com os feminismos, e nuances de interseccionalidade de gênero, em que pese nas contribuições estudadas não essa categoria não possuir centralidade. Suas críticas gravitam no economicismo como "centralidade na raiz econômica de todas as relações, desconsiderando o aspecto cultural", culturalismo "excesso de análise cultural e baseada na identidade", "antidualismo pós - estruturalista" (completa desconstrução da distinção entre economia e cultura", afirmando: nenhuma das três abordagens fornece uma 
teoria aceitável da sociedade contemporânea. A partir de então, propõe ancorada na teoria crítica, a "interconexão" entre Reconhecimento e Redistribuição em suas elaborações, sendo esses interpretados como mecanismos de Justiça.

\section{CONSIDERAÇÕES PRELIMINARES}

Constituiu-se especial desafio, analisar as obras de duas militantes feministas ${ }^{9}$ com lastro de produção e reconhecimento no interior tanto do ativismo, quanto acadêmico. Igualmente, analisar essas contribuições, a partir do conceito ampliado de justiça, intencionando interpretar esses conceitos com a luz teórica da crítica à justiça e ao direito na sociedade do capital.

Sabe-se que para análise ampliada dos fenômenos sociais, é imprescindível superar o “terreno do Direito", permeada por um viés “técnico - jurídico". Analisar a prática da Justiça sob a ótica da interligação interseccional em Davis, e da conexão de reconhecimento, redistribuição e representação, em Fraser, nos leva a romper com a análise automatizada dos "sujeitos de direitos", particularizando opressões históricas no primeiro e reordenando as táticas de enfrentamento a processos excludentes na segunda.

O processo de análise das obras das autoras levou a algumas indagações: Quem tem direito em uma sociedade contemporânea, que tem como norma o masculino, a branquitude, e a heterossexualidade? Qual é o espaço desses sujeitos na busca por acesso aos direitos? Qual é a análise daqueles que operam o jurídico, para as particularidades históricas, econômicas, culturais, sociais dos sujeitos? Quem são aqueles que recebem o "julgo/cetro/balança" do operador do direito, em especial na realidade brasileira, que possui contornos e processos de formação social mais intensificados e particulares, do que propriamente dito da América do Norte, lugar de pesquisa das autoras. É importante reposicionar essas reflexões, para intencionar romper com uma voz única propiciando outros lugares - outras perspectivas que rompam com uma história social única, que não reflete a realidade dos sujeitos.

Em Fraser e Davis, identificamos elementos que as diferenciam no método de análise e na forma de interpretação dos fenômenos sociais. Ao nosso ver, Davis almeja a construção de um novo tipo de sociabilidade, pois, a força motriz do capitalismo está nas opressões,

\footnotetext{
${ }^{9}$ Destaca-se aqui, que as obras estudadas das autoras, são as que se encontram nas referências. Portanto, nos limites de um artigo e na lente metodológica que nos torneia, não nos arriscamos a dizer que estes são os achados finais do estudo e sim percepções das contribuições das autoras que tivemos acesso, no que diz respeito à concepção de justiça.
}

Vol. 02, N. 03, Jul. - Set., $2019 \cdot$ www.revistas.unilab.edu.br/index.php/rebeh 
tendo a questão do racismo centralidade, se conectando e interseccionando com gênero e classe.

Já para Fraser, crítica do momento "pós socialista", acredita que é possível no redudistribuição das riquezas e o reconhecimento sejam centrais". (FRASER, 2003, p. 78, apud CASTRO, 2010). Importante frisar que Fraser não defende em suas elaborações um modelo distributivo liberal, mas sim uma outra via, entre as políticas socialistas transformadoras e as políticas reformistas liberais, denominada de "reforma não reformista" (FRASER, 2003, apud CASTRO, 2010).

Entendemos que as duas autoras possuem proposições analíticas importantes na maneira de problematizar a sociedade sobre o prisma de grupos sociais, minorias étnicas, com enfoque em gênero, raça e classe, ainda que equidistantes uma da outra. Em contexto de capitalismo mundializado, temos a contradição como elemento fundante, sendo presentes também no direito e na concepção de justiça. Assim, ao mesmo tempo que almejamos a construção de uma nova sociedade com parâmetros justos, igualitários e socialização dos meios de produção, como pode-se observar na teoria de Davis, na atualidade "enquanto se constrói o amanhã" é possível buscar medidas que possibilitem a ampliação de direitos no capitalismo. De forma análoga, identificamos a política social, que em seu conteúdo e essência é contraditória, por vezes vista como reformista, porém no contexto do capitalismo da barbárie, promove mudanças e acessos na vida das pessoas diariamente, ainda que, sem contestar a ordem do capital, vez que ao fim e ao cabo contribui para o seu processo de reprodução social.

Assim, em Davis, temos a centralidade da injustiça racial como fator primeiro das desigualdades e opressões, desde o processo escravagista, sendo visível na atualidade com as questões étnicas transnacionais, por exemplo.

Já Fraser, feminista da teoria crítica, provoca uma nova tática para a esquerda, na qual reconhece os equívocos do movimento "pós socialista", a ascensão do multiculturalismo, apresenta as armadilhas escorregadias dos feminismos, e diante disso propõe aos movimentos de "esquerda" um reordenamento das estratégias e táticas de forma, ao seu ver, torná-las factíveis.

Para finalizar nosso texto, indicamos que essas leituras precisam ser auxiliadas pelos textos da juventude de Marx, especialmente os escritos que elucidam a distinção entre emancipação política e emancipação humana, que contribuíram significativamente para relação estreita desses temas com o debate sobre a justiça. 


\section{Referências}

ALMEIDA, Silvio Luiz de. O marxismo de Ângela Davis. 2016. Blog da Boitempo. In: $\mathrm{N} 5 \mathrm{C}$ https://blogdaboitempo.com.br/2016/09/26/0-marxismo-de-angela-davis/. Acesso em: 02/01/2019.

BRASIL. Ministério da Justiça. Levantamento nacional de informações penitenciárias. Infopen Mulheres, Junho de 2014.

DAVIS, Ângela. Mulheres, Cultura e Política. Tradução Heci Regina Candiani. $1^{\text {a }}$ ed. São Paulo: Boitempo, 2017.

DAVIS, Ângela. Mulheres, Raça e Classe. Tradução Heci Regina Candiani. $1^{\mathrm{a}}$ ed. São Paulo: Boitempo, 2016.

DAVIS, Ângela. A liberdade é uma luta constante. São Paulo: Boitempo, 2018.

FERREIRA, Walace. Justiça e reconhecimento em Nancy Fraser: interpretação teórica das ações afirmativas no caso brasileiro. Perspectiva Sociológica, v. 5, p. 1. Disponível em: http://www.cp2.g12.br/UAs/se/departamentos/sociologia/pespectiva_sociologica/Numero4/Ar tigos/wallace.pdf. Acesso em 15/01/2019.

FRASER, Nancy. Dossiê: Contribuições do pensamento feminista para as ciências sociais. O feminismo, o capitalismo e a astúcia da história. Mediações, Londrina, v. 14, n.2, p. 11-33, Jul/Dez. 2009

FRASER, Nancy. Entrevista "uma feminista propõe repensar a esquerda". Site Outras palavras. In: https://outraspalavras.net/outrapolitica/uma-feminista-propoe-repensar-aesquerda/. Acesso em: 07/01/2019.

FRASER, Nancy. Para uma crítica das crises do capitalismo: Entrevista com Nancy Fraser. Perspectivas, São Paulo, v. 49, p. 161-185, jan./jun. 2017

FRASER, Nancy. Reconhecimento sem ética. Lua Nova, São Paulo, 70: 101-138, 2007. Artigo originalmente publicado na revista Theory, Culture \& Society, v. 18, p. 21-42, 2001. Tradução de Ana Carolina Freitas Lima Ogando e Mariana Prandini Fraga Assis.

FRASER, Nancy. Redistribuição ou reconhecimento?Classe e status na sociedade contemporânea. Conferência: Intersecções - R. de Est. Interdisc., UERJ, RJ, ano 4, nº 1, p. 7-32, jan/jun. 2002.

MASCARO, Alysson Leandro. Introdução ao Estudo do Direito. $4^{\text {a }}$ edição. São Paulo: Atlas, 2013.

MARCARO, Alysson Leandro. Filosofia do Direito. 4a edição. São Paulo: Atlas, 2014.

MASCARO, Alysson Leandro. Direitos Humanos: uma crítica marxista. Lua Nova, São Paulo, 101: 109-137, 2017 
MASCARO. Política e crise do capitalismo atual: aportes teóricos. Revista Direito e Práxis. Rio de Janeiro. Vol. 9, N. 1, 2018, p. 46-69.

RIBEIRO, Djamila. A utopia de Ângela Davis. 2016. Blog da Boitempo, In: D 5 D CII https:/blogdaboitempo.com.br/2016/06/09/a-utopia-de-angela-davis/. Acesso em: $02 / 01 / 2019$.

SARTORI, Vitor Bartoletti. Lukács e a crítica ontológica ao direito. São Paulo: Cortez, 2010.

SARTORI, Vitor Bartoletti. Direito e socialismo?A atualidade da crítica de Marx e Lukács ao Direito. Revista Direito e Práxis, vol. 5, n. 9, 2014, p. 277-300.

TADINI, Giulia. Uma breve introdução a Nancy Fraser. Revista Movimento. In: https://movimentorevista.com.br/2018/02/uma-breve-introducao-a-nancy-fraser/. Acesso em: $14 / 01 / 2019$.

Recebido em: 18/04/2019

Aceito em: 18/12/2019 